\title{
O CONTRIBUTO DAS CONGREGAÇÕES RELIGIOSAS PARA A EDUCAÇÃO TRADICIONAL DA MULHER EM PORTUGAL*
}

\author{
Justino Pereira de Magalhães**
}

SÍNTESE - O factor religioso foi uma componente fundamental da educação tradicional. Nas sociedades tradicionais, a mulher assumiu a delicada função de preservar as memórias e as práticas tradicionais de educação das gerações jovens. Assim, a vigilância do comportamento religioso da mulher foi muito rigorosa. As congregações religiosas, designadamente a Congregação das Ursulinas, assumiram a partir do Concílio de Trento a principal função de ensinar e educar as mulheres. Com efeito, quando se instalaram em Portugal no século XVIII, as Ursulinas tinham já uma longa experiência noutros países europeus. Esta Congregação foi criada em França, no contexto histórico da Reforma Católica. A sua principal estratégia para educar e converter as populações ao Cristianismo foi ensinar as mulheres a ler e escrever. A alfabetização feminina foi uma via para combater a Reforma Protestante e para consolidar um texto religioso no interior da sociedade, uma vez que as mulheres eram o suporte principal da tradição oral religiosa. A Congregação das Ursulinas desenvolveu um importante método para ensinar as mulheres a ler e escrever. Na sua Constituição, a alfabetização e as demais dimensões educacionais eram fundamentais. Este texto é um contributo para a história da educação tradicional das mulheres em Portugal, através do estudo da acção das Ursulinas.

PAI_AVRAS-CHAVE - congregações religiosas, educação tradicional, mulher.
ABSTRACT - The religious factor has been a fundamental component of the traditional education. In the traditional societies, the women assumed the delicate function of preserving the memories and the traditional practices, of educating the new generations. The social vigilance to the women's religious behaviour has been very rigorous. The religious congregations, for instance the Ursulines Congregation, assumed the principal function to teach and to educate the women, since the Council of Trento. Therefore when the Ursulines were created, in Portugal, at the XVII century, they have a long experience in the other european countries. This Congregation has been created in France, into the historical contexte of the Catholic Reform.Their principal strategie to educate and to convert the people to Christianity, was teaching the women to read and to write. The women literacy was an way to fly back against the Protestant Reform, and an way to consolidate a writed religious text within society. In fact, the women was the principal support of the religous traditional orality. The Ursulines Congregation has developed an important method to teach the women to read and to write. In their constitution, the literacy and the other educational dimensions, was very important. This paper is a contribution for the history of women's traditional education in Portugal by studying the ursulines' action.

KEY WORDS - religious congragations, traditional education, women.

* Comunicação apresentada na International Standing Conference for the History of Education ISCHE (ISCHE XIX) - Irlanda XIX, 1997.

** Instituto de Educação e Psicologia da Universidade do Minho. / Braga - Portugal.

\begin{tabular}{|l|l|l|l|l|l|} 
VERITAS & Porto Alegre & v. 43 & $\mathrm{n}^{\mathbf{0}}$ especial & Dezembro 1998 & p. 151-157 \\
\hline
\end{tabular}


1. Na sociedade ocidental do Antigo Regime, a educação da mulher e a educação do homem eram distintas. Um processo de diferenciação que varia de região para região, em conformidade com o período histórico e com o estatuto sociocultural. Genericamente e de forma sumária, pode todavia afirmar-se que tal processo vinha a acentuar-se desde finais da Idade Média, como resultado de uma normatização das relações sociais, associada às reformas religiosas, à afirmação do indivíduo e a uma maior diferenciação entre público e privado. Não apenas aos homens e às mulheres estavam confiadas diferentes tarefas, como diferentes eram as expectativas, papéis e projectos. Assim no plano religioso, às obrigações comuns contrapunham-se, no quadro familiar, funções de controlo e vigilância, devidas ao homem, e funções de doutrinação, ritualização e encomendação, devidas à mulher. Ainda no quadro familiar, à necessária complementaridade, quer da força laboral, quer dos réditos, cabia à mulher o principal desempenho das funções domésticas e ao homem a relação ao exterior (cf. Shorter, 1995). Também no que se refere ao acompanhamento e à educação dos filhos, à prevalência da mãe junto da infância, contrapunha-se uma gradual aproximação do pai a partir dos 7/8 anos, sobretudo para os rapazes.

Diferenciações que se alargam das relações de trabalho, às oportunidades e às perspectivas de vida, envolvendo diferentes estratégias, seja no plano individual, seja no plano grupal e/ou societário. Neste contexto, a educação não apenas reflecte os distintos quadros de referência, como constitui um factor fundamental na construção de representações, práticas e destinos de vida igualmente distintos para o homem e para a mulher. Assim se à mulher estavam destinadas uma prevalência no lar e uma função sociocultural essencialmente conservadora, a sua educação não podia deixar de reflectir, designadamente, uma dominância do privado, face ao público, como de idêntico modo se ressentia da prevalência do factor religioso e das vertentes formativa e endoutrinadora, face às dimensões instrutiva e de eventual renovação.

Por outro lado, sendo então as memórias, social, grupal e individual muito dependentes de suportes orais, pela mulher passava uma importante função, transmitinđo às gerações vindouras o que havia de mais sagrado, mas também de mais sigiloso e privado. Funções e representações que convertiam a participação sociocultural da mulher, simultaneamente em necessidade e em factor de suspeição e controlo. Assim pois um estatuto marcado por uma autonomia ideológica e socialmente mitigada. Também os avanços científico e da medicina acerca da natureza humana não se revelavam suficientes como contraponto aos preconceitos de uma distinção entre a alma masculina e alma feminina.

Será sobretudo pela via do trabalho, associado à nuclearização das famílias, que a mulher encontrará uma base mais sólida de igualitarização de direitos, oportunidades e representações. Um processo bem mais pacífico entre os estratos sociais tradicionalmente ligados à produção, mas que não deixará de ser fundamental para outros sectores da sociedade. 
2. A semelhança do que sucedia para o sexo masculino, o século XVII ficara marcado pelo desenvolvimento de instituições de educação e formação para o sexo feminino. São instituições de base religiosa, datando, no caso português, do século XVII, a criação das primeiras escolas régias femininas, que no entanto não entraram em funcionamento. A escolarização da educação feminina, para além de proporcionar o ensino da leitura, traduz-se num vasto programa formativo que inclui economia doméstica e formação religiosa, preparando a rapariga para a gestão da vida doméstica, para mulher e mãe. Um processo de escolarização que afastava as alunas da prática de certos exercícios físicos e de que resultava não apenas a acentuação da debilidade física da mulher, como o seu afastamento do desempenho de certas funções e papéis, numa manifesta menoridade, seja no plano doméstico, seja no plano social. Com efeito, a complementaridade de funções e de réditos, associada designadamente aos processos de industrialização e à nuclearização da vida familiar, não se revelou suficiente para gerar uma igualdade de representações. Ou seja, adoptando a conceptualização de Sousa Santos, pode concluir-se que a uma eventual proximidade entre o "espaço doméstico" e o "espaço do trabalho" se contrapunha uma heterogeneidade com o "espaço da cidadania" (Santos, 1990; Araújo, 1996).

À escola, como principal instância de formação e de socialização coube por consequência um papel fundamental na produção e apropriação de valores, saberes, práticas e representações. Todavia, apesar do avanço da laicização e da multiplicação das escolas para o sexo feminino é com as reformas de sentido compreensivo que marcam o período entre as duas Guerras Mundiais que se observam orientações claras da política e da cultura escolares tendentes a uma verdadeira instituição da igualdade.

3. No decurso do século XIX e primeira metade do século XX, em Portugal, a Instrução Elementar, quer no plano teórico e normativo, quer ao nivel da sua aplicação, prosseguiu orientações pedagógicas e curriculares distintas para ambos os sexos. Uma diversificação de percursos escolares que geralmente se traduzia pela simplificação das componentes instrutivas face a uma ampliação das componentes formativas de economia doméstica, labores e outras, mas que acentuava uma lógica de funcionamento pedagógico e didáctico, sob a estrutura de curso. Com efeito, não se criaram Cadeiras de Primeiras Letras para o sexo feminino, mas sim Escolas, absorvendo ou não as Mestras de Meninas. A lei de 15 de Novembro de 1836 apenas previa uma escola de meninas em cada capital de distrito, não perfazendo as 53 escolas femininas existentes em 1854, mais que 4,4\% das 1.199 escolas do ensino elementar. No meio século seguinte, a relação de escolas femininas elevou-se para cerca de $30 \%$ das cerca de 4.500 escolas. O ensino doméstico e particular era muito usual para um e outro sexo, embora assumisse maior relevo para o sexo feminino e houvesse mestras aprovadas, em cujo alvará não constava o ensino da leitura (cf. Magalhães, 1994, p. 218). Uma formação laboral que não constitui todavia, uma iniciação à produção, uma vez que se destinava a complemento e suporte da economia doméstica. É todavia uma formação compatível com a de mulher-leitora. 
Também a política educativa dos republicanos visava um tratamento diferenciado, ainda que não discriminatório para o sexo feminino. Não obstante, a escolarização da formação feminina, iniciando ao mundo laboral e ao mundo da burocracia e do secretariado, representa um passo fundamental na igualitarização de oportunidades e na superação das representações discriminatórias. Também para Portugal, a mudança de finalidades da escolarização da mulher está ligada à sua socialização, desenvolvendo-se, no plano histórico, de uma focalização na futura mãe de familia para uma futura produtora.

4. Se até meados do século XX a escolarização contribuiu, nos planos instrutivo e formativo, para a diferenciação, entre os sexos masculino e feminino, poderse-á admitir-se que a instrução religiosa, facultada ao nível da catequese, era igual para ambos os sexos? Como se poderá de igual modo perguntar se os processos tradicionais de iniciação à leitura e à escrita, ligados ou não à catequese, constituiam de igual modo um factor de diferenciação. A resposta não pode ser dada de forma genérica, uma vez que não apenas as experiências de ensino de Primeiras Letras levadas a efeito por eclesiásticos se tornaram extensivas, em algumas circunstâncias, a um e outro sexo, como há circunstâncias, no decurso do século XIX, em que o acesso à alfabetização se manteve mais condicionado por factores socioeconômicos, que pelo factor género. Assim, para alguns concelhos rurais do Norte de Portugal, em que a inexistência de escolas para o sexo feminino não fora factor impeditivo de, contrariamente às orientações da legislação, os professores, perante a pressão dos pais, admitirem alunos de um e outro sexo (cf. Magalhães, 1996).

Um recurso todavia que se confinava à alfabetização e com maior incidência na leitura, uma vez que desde finais do século XVII, como se afirmou, as Escolas Femininas de Instrução Elementar apresentavam um programa e actividades para além da instrução, o que gerava algumas limitações na aprendizagem e fazia com que as taxas de aprovação feminina nos exames da instrução primária elementar fossem também reduzidas.

5. A Congregação das Ursulinas que se organizara em Portugal no decurso do século XVIII era uma instituição verdadeiramente vocacionada para a educação das jovens. Instituídas no contexto da Reforma Tridentina, como frente avançada para o ensino da leitura em zonas agitadas pela Reforma Protestante, sobretudo em França, as Ursulinas desenvolveram um plano de educação para o sexo feminino, vindo mais tarde a espalhar-se por outras zonas da Europa, incluindo Portugal. Agentes da Reforma Tridentina, apenas em parte se contrapõem aos Jesuitas, para o sexo masculino, uma vez que as Religiosas centram a sua acção no plano da iniciação e prática da leitura e da escrita, enquanto os Colégios da Companhia de Jesus recebiam estudantes já preparados para entrarem na Gramática Latina.

São todavia duas Congregações que tomam a instrução e a formação como meios fundamentais de conversão e de controlo comportamental. Duas experiências pedagógicas e didácticas, enraizadas num mesmo modelo, uma mediatização da sociedade real, para a sociedade idealizada. Com efeito, entre o modelo organizacional dos colégios humanistas e a organização hierarquizada e estamental da 
sociedade do Antigo Regime, há uma grande analogia o que não apenas legitima e fundamenta o processo educativo, como the dá maior eficácia pedagógica, preparando os colegiais para os lugares cimeiros da estrutura social. Institucionalmente o processo pedagógico dos colégios caracteriza-se pela existência de: 1) uma disciplina com prémios, castigos, promoções e humilhações; 2) uma estrutura de poder, com hierarquia e diversidade de funções; 3) uma ordem de classes nas quais os alunos se distribuem segundo as suas idades; 4) um método; 5) uma organização do tempo; 6) uma organização do espaço; 7) uma organização do saber; 8) um regulamento.

Porém, a mulher educada não se destinava a uma vivência pública, pelo que a sua formação é fundamentalmente um reforço e um prolongamento do privado. Esta a questão fundamental uma vez que a educação do rapaz se traduz num reforço do público, ou melhor numa (des)privatização, enquanto o processo de formação da mulher é essencialmente um processo de (re)privatização. Uma dialéctica estruturante das relações social e familiar, pois que, para um e outro sexo, o essencial da formação não discriminava leigos e professos.

6. "Sendo especialmente estabelecidas para se empregar na instrução e conduta de meninas e obrigadas pelas suas Constituições a receber com este desígnio educandas nos seus mosteiros, é necessário a fim de que elas [as Ursulinas] se possam bem desempenhar que todas as classes estejam por ordem sem confusão e os ofícios daquelas que nisso se empregam sejam regulados de sorte que cada uma sem detrimento da sua própria perfeição possa procurar a das meninas que lhe são cometidas" (Regulamento para as Religiosas Ursulinas, Capítulo 1). Neste sentido, o Regulamento era uma estrutura organizativa, cujas valências não se esgotavam nos espaços internos, uma vez que em cada mosteiro haverá um apartamento das Educandas, constituido por dormitório com celas, salas grandes, com camas separadas por cortinas, um oratório, uma rouparia com armários individuais para a roupa branca, uma cozinha com despensa, um refeitório, destinados à educação de meninas.

Para além da Prefeita das Educandas, haverá uma mestra de escrever, uma mestra da conta e da ortografia, uma mestra dos instrumentos e mestras que ensinam a ler o vulgar e o latim, etc., mestras de renda, costura e de toda a casta de lavores, para além das que cuidam da roupa, das que penteiam e vestem as crianças. As educandas distribuir-se-ão por seis classes conforme o seu adiantamento e, no refeitório, observarão o silêncio, a benção da mesa, a leitura e a acção de graças como as Religiosas.

À Madre Prefeita das Educandas, que em tudo respeitará a Madre Superiora, cabe zelar para que as Mestras das classes cumpram com as suas obrigações, bem como a relação com os familiares. Regularmente fará advertências às educandas, cabendo à Mestra da Instrução de meninas, a assistência e o seu acompanhamento sistemático das educandas, bem como a formação espiritual e moral. Os exercícios espirituais constituem a base estruturante do dia-a-dia das educandas, com recorrências cíclicas desde o levantar ao deitar, numa analogia com a vida 
real: ao levantar, através de uma oração breve entregarão o seu coração a Deus, mais tarde, no oratório, oferecer-lhe-ão os actos do dia, fazendo ainda meia hora de oração mental antes da missa. Após o almoço dividir-se-ão pelas classes. Antes do jantar recolherão em exame de consciência, sendo a refeição acompanhada de leitura. A seu tempo, as educandas não deixavam de preparar-se para a Primeira Comunhão, para a Confirmação e restantes Sacramentos.

Cađa manhã as educandas serão recebidas pelas Mestras de Renda, Costura e toda a casta de Lavores, até que cheguem as restantes Mestras, podendo entretanto algumas educandas prepararem as suas lições. À tarde, de novo após a hora da doutrina, estas Mestras estarão presentes nas Classes, podendo recorrer às educandas mais adiantadas para apoiarem as colegas. Após a merenda terão uma hora para estudo e para leitura, podendo ainda aplicar-se em alguma manufactura até a ceia. À noite, enquanto as mais pequenas se vão deitar, as mais velhas retomarão os seus trabalhos, até a hora da lição, exame e ladainha. No Verão, após a ceia terão ainda uma hora para se divertirem e passear na cerca, ou em outro local.

As grandes festividades anuais eram respeitadas e constituiam motivo de preparação adequada. As actividades escolares eram interrompidas todas as quintasfeiras, sempre que não houvesse outro dia santo na semana, bem como entre o dia de Natal e a Epifania, nos três dias de Carnaval, entre o Domingo de Ramos e a Pascoela, e desde o último dia de Agosto a quinze de Setembro para as mestras fazerem os exercícios de Sto. Inácio.

7. Tomado, apenas nestas dimensões educacionais e formativas, posto que o Regulamento é bem completo quanto aos métodos e tempos de ensinar e aprender as restantes matérias, pode concluir-se que o quotidiano é integralmente tomado como matéria, estrutura e argumento da formação. Os tempos, os espaços, as acções, a reflexão são organizados por rotinas e orientados por uma metaeducação, assente nos principios de informação, disciplinação, ordem, respeito, trabalho, ocupação, dever, mas também economia, bem-estar, conformidade, perfeição e exercício. Uma educação centrada nas vivências domésticas, em que o sagrado e o profano se imbricam num misto de individuação, abnegação, mas também informação e formação. Não apenas a leitura é uma via de alargamento da informação, como o ensino da catequese deveria ser feito com base em "hestórias" e através de analogias com o quotidiano. Uma diferenciação face à educação do sexo masculino, ou antes um quotidiano no feminino, uma educação do/ no feminino? Se alguma educanda revelasse vontade de professar, deveria voltar ao "mundo" para que mais livremente fizesse a sua opção.

A leitura, a escrita e a contagem eram meios para um mesmo objectivo - a sacralização do quotidiano do destino de vida, um meio de conversão e de expansão da religião, junto das educandas e das suas famílias, quer enquanto crianças, quer depois como mulheres e mães. A leitura era uma forma de preservação do texto sagrado básico, a garantia da sua transmissão sem interpretações, ou intermediários. Uma estratégia idêntica à das Religiões Reformadas. 
Cada Colégio ou Mosteiro teria uma classe, em casa separada, destinada às crianças pobres que diariamente a frequentariam, em regime de externato. Também aqui, para além do rigor na admissão das crianças, esperavam as religiosas afectar através das educandas as familias, designadamente os pais, transferindo para eles responsabilidades concretas no acompanhamento das filhas após saírem da classe. De novo uma focalização na oração, no dever, no respeito, uma articulação do real com o religioso, pela prática regular do exercício espiritual e pela transferência para os pais de uma alteridade e de uma regulação do ritual e do sagrado.

Instâncias de (in)formação, as estruturas educativas religiosas no Período Moderno facultaram experiências fundamentais na escolarização de saberes e de práticas do quotidiano, legitimando e produzindo funções, papéis e representações simbólicas diferenciadas entre masculino e feminino. De igual modo contribuíram para uma integração da família nuclear, fomentando uma aproximação relacional entre pais e filhos e diferenciando, no espaço doméstico, as funções da mulher e as funções do homem. Uma racionalidade pedagógica assente no isomorfismo entre a formação no espaço escolar e o desempenho de funções e papéis na vida real e na sacralização do quotidiano.

\section{Referências bỉbliográficas}

ADÃO, Aurea. Estado absoluto e ensino das Primeiras Letras: as Escolas Régias (1772-1794). Lisboa: Faculdade de Ciências, Universidade de Lisboa, 1995. v. 1 e 2.

ADB (Arquivo Distrital de Braga). Regulamento para as Religiosa Ursulinas. (Fundo MonásticoConventual, Pasta U-16, Doc.3. Manuscrito).

ARAÚJO, Helena. "Precocidade e 'retórica' na construção da escola de massas em Portugal". Educação, Sociedade \& Culturas, n. 5, p. 161-174, 1996.

BOIRAUD, Henri. La condition féminine et la scolarisation des filles en France au XIXème siècle de Guizot a Jules Ferry. Caen: Université de Caen, 1978.

FERNANDES, Rogério. Os caminhos do ABC. Sociedade portuguesa e ensino do Primeiras Letras do Pombalismo a 1820. Porto: Porto Editora, 1994.

MAGALHÃES, Justino. Ler e escrever no mundo rural do antigo regime. Um contributo para a história da alfabetização e da escolarização em Portugal. Braga: Universidade do Minho, Instituto de Educação, 1994.

- - "Um contributo para a história do processo de escolarização da sociedade portuguesa na transição do antigo regime". Educação, Sociedade \& Culturas, n. 5, p. 7-34, 1996.

—_. "A instabilidade da política educacional em Portugal no século XIX. O Caso da Póvoa de Lanhoso". In: História da coragem feita com o coração. Actas do Congresso "Maria da fonte - 150 Anos" 1846/ 1996. Póvoa de Lanhoso: Câmara Municipal da Póvoa de Lanhoso, 1996. p. 91-95.

- "Origens e formação cultural dos Beneditinos do Brasil no periodo colonial". Revista Portuguesa de Educação, v. 9, n. 1, p. 107-118, 1996.

NÓVOA, António. Le temps des professeurs - analyse socio-historique sur la profession enseignant au Portugal (XVII ${ }^{e}-\mathrm{XX}^{\mathrm{e}}$ siècles). Lisboa: INIC, 1987. v. 1 e 2.

SHORTER, Edward. A formação da família moderna. Lisboa: Terramar, 1995.

SONNET, Martine. L'éducation des filles au temps des lumières. Paris: Les Éditions du CERF, 1987. 